\title{
Engineering Education, Moving into 2020s: Essential Competencies for Effective 21st Century Electrical \& Computer Engineers
}

\author{
Junaid Qadir ${ }^{1}$, Kok-Lim Alvin Yau ${ }^{2}$, Muhammad Ali Imran ${ }^{3}$, Ala Al-Fuqaha ${ }^{4}$ \\ ${ }^{1}$ Information Technology University, Lahore, Pakistan \\ ${ }^{2}$ Sunway University, Malaysia \\ ${ }^{3}$ University of Glasgow, UK \\ ${ }^{4}$ Hamad bin Khalifa University, Qatar; Western Michigan University, USA
}

\begin{abstract}
Full Paper: Research-to-Practice) As we move into the third decade of the $21 \mathrm{st}$ century, the $2020 \mathrm{~s}$, the unprecedented rate of technological disruption and the short-lived nature of the specifics of engineering state-of-the-art require us to carefully evaluate what it takes to be an effective engineer and what this entails for engineering education and their lifelong learning. While it is true that certain basics of engineering will not change, there will be an increased premium for some skills (such as lifelong learning, meta-learning, collaboration, creativity, critical thinking, communication skills, and cultural/global literacy). 21stcentury skills are, as such, timeless skills: it is paradoxically the volatile nature of the modern world that has forced us from ephemeral vocational fads back to these permanently valuable skills. In this work, after reporting on the skills that policy tanks and thought leaders deem necessary for the 21 st century, we provide a synthesis in which we describe the pulls and pushes that learners and educators will face in the turbulent times of 2020 and beyond, and how they can thrive in the uncertain future through holistic well-rounded engineering education.
\end{abstract}

\section{ENGINEERING EDUCATION IN THE 2020S}

We live in a dynamic era that offers great opportunities and also poses unprecedented challenges. The exponential advances in the instrumentation, computational, and communication, capabilities of modern devices create a mind-boggling world of opportunities for the next generation of electrical and computer engineers. As we begin our journey into the 2020s, things are going to change and one must anticipate and adapt to these trends. The third decade of the third millennium has begun ominously with the global spread of the COVID-19 pandemic, the biggest for more than 100 years. In the coming years, technological forces lead by artificial intelligence will interact vigorously with policies such as globalization to create a very different future. In this paper, we ruminate on what education will best serve electrical and computer engineers in the 2020s and beyond.

\section{A. How have the Desired Skills Evolved Over the Years?}

Over the past 150 years, the economic growth has evolved from the agriculture age to the industrial age, the information age, and finally as affluence, technology, and globalization have become prominent, the conceptual age [1]. In the conceptual age, there is a need to integrate creativity, empathy, and innovation into knowledge. This accentuates the need for skills such as design (aesthetic and emotive designs), story (context and narrative facts), symphony (big pictures comprised of multiple facets), empathy (a high-touch customer relationship), play (a sense of humor), and meaning (meaningful works with similar values) [1].

\section{B. Jobs in the 21st Century Demand New Skills}

In the 21 st century (21C), with the rise of artificial intelligence (AI) and robotics technology, the gap between the jobs performed by humans and machines, and those jobs that are creative and those that are routine, is rapidly closing. To this date, the assertion "one machine can do the work of fifty ordinary men. No machine can do the work of one extraordinary man" by Elbert Hubbard, a 19th century American author, still holds true-albeit in a greatly diminished space as AI technology has made great strides in automating many perception and prediction tasks. In this new era, creative works, which require abstract problem solving and mental flexibility [2], have become more important and high-paying. It is important that the focus in education circles to keep up with the times but the challenge is stark. Richard Riley, Former US Secretary of Education, described this challenge as: "We are currently preparing students for jobs that don't yet exist, using technologies that haven't been invented, in order to solve problems we don't even know are problems yet."

\section{Electrical and Computer Engineering Education}

In a report by Harvard professors, engineering is stated to have become an "essential core knowledge for every broadly educated person and an indispensable background for leaders." [3]. Engineering education has been regarded as the new "liberal arts degree" for the 21st century since it includes important technological literacy that is essential in today's world [4]. It is anticipated that electrical and computer engineering will play a big role in solving the biggest problems facing the society, some of which have been designated by the National Academy of Engineering (NAE), USA, as the "engineering grand challenges". Addressing these huge multidisciplinary challenges pertaining to the life, physical and engineering sciences-such as brain reverse-engineering, medicine engineering, health informatics, personalized learning, access to clean water-puts an impetus on focusing our energies on developing effective electrical and computer engineers for beyond the 2020s. 
According to the NAE [5], two sobering realities related to engineering education are emerging. First, that interventions are scattered across engineering education over the past decade and this has not brought about a systemic change, rather the successes of individual programs and campuses are isolated instances. Secondly, there is increasing isolation between engineering education and practice. The issue lies in the fact that that there has been an explosion of knowledge, the need to integrate into the global economy, and that societal problems have become more complex, interconnected, and of wider reach in the world. Engineering students are generally given mathematical and formulaic problems requiring them to perform unwieldy manipulations that clutter the main concepts and interfere with learning, or to follow guidelines and rules in search of cookbook solutions that suppress creativity and fail to gauge their understanding [6]. Not only is the focus of engineering education narrow, its relevancy to the interdisciplinary nature of today's world is questionable.

\section{Contributions and Organization of This Paper}

It is increasingly important for electrical and computer engineers of 2020s to be ready for the future of a world that has become volatile, uncertain, complex, and ambiguous (VUCA). In this regard, it is important to think about the list of essential attributes that these engineers should have and what principles should they be aware of. This topic has been the focus of multiple studies in the past [7] [8] [9] [10], including two NAE reports on the vision of engineers of 2020 (published in 2004 [11]) and on educating the engineer of 2020 (published in 2005 [12]). Apart from citing and leveraging the rich literature on this topic, we also utilize our experiences as electrical and computer engineering educators, administrators, and practitioners to inform our list. Our paper will be a handy reference for engineering educators, leaders, as well as students. The remainder of the paper is organized in the following way. In Section II, the prior work on 21st century electrical and computer engineering education is described. In Section III, the essential competencies of electrical and computer engineers for the 2020s and beyond are described. Finally, the paper is concluded in Section IV.

\section{Prior Work on 21St Century Electrical AND COMPUTER ENGINEERING EdUCATION}

The history of electrical engineering education [13] shows that there have been five major shifts in 100 years of engineering education [14]. Due to the dramatic expansion of knowledge and the new challenges posed by the 21 st century, much attention has focused on adapting the engineering education system to the needs of 21st century engineering [7], [10], [15][18]. Although the engineering fundamentals do not change, the explosion of knowledge, the unpredictable global economy, and the way in which engineers work (e.g., the worldwide marketplace of engineering services, and the engineering jobs that move freely) reflect an ongoing evolution that cry out for 21 st century skills. Several 21 st century skills have been proposed with considerable overlap among them. We restrict our focus mainly on the three most popular frameworks next.

\section{A. NRC Defined 21st Century Skills Framework}

As a first step toward describing "21st century skills," the National Research Council (NRC), building upon previous efforts to categorize dimensions of human knowledge, proposed a framework covering three domains of competence [15] cognitive, interpersonal, and intrapersonal-which represent distinct facets of human thinking. The framework is based on Bloom's 1956 taxonomy of learning objectives that includes three broad domains-cognitive (related to knowing), affective (related to feelings), and psychomotor (related to doing). Based on the Bloom's taxonomy, the cognitive domain covers thinking and related abilities (e.g., memory, reasoning, and problem solving). The intrapersonal domain covers emotions and feelings, as well as self-regulation, which is the ability to manage one's emotions, as well as set and achieve one's goals [19], and it is like Bloom's affective domain. The interpersonal domain covers the expression of information to others and collaboration with others, and it is not included in the Bloom's taxonomy. Various 21st century skills are clustered into the cognitive, intra-personal, and interpersonal domains [15] as shown in Fig. 1.

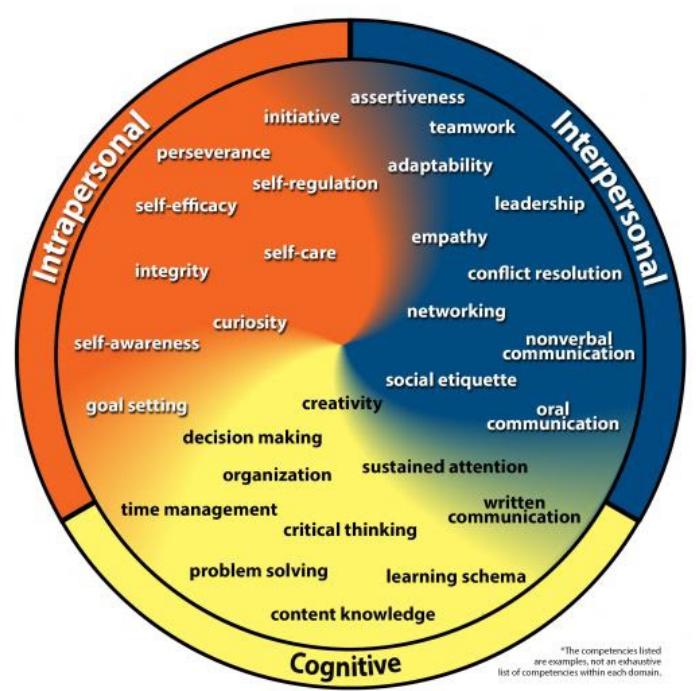

Fig. 1: NRC-defined 21st century skills framework (Credit: [15]).

\section{B. ATC21s Defined 21st Century Skills Framework}

Major corporations, including Cisco, Intel, and Microsoft, through a sponsored project headquartered at the University of Melbourne, propose the Assessment and Teaching of 21st Century Skills (ATC21s) framework to address the shortcoming of formal education systems which have not kept pace with the changing needs of the times. The framework, also called the knowledge, skills, attitudes, values, and ethics (KSAVE) framework, groups ten skills-(1) creativity and innovation; (2) critical thinking, problem solving, decision making; (3) learning to learn/ metacognition (knowledge about cognitive processes); (4) communication; (5) collaboration (teamwork); (6) information literacy; (7) ICT literacy; (8) citizenship-local and global; (9) life and career; and (10) personal and social responsibility-including cultural awareness and competenceinto four categories [20] as shown in Figure 2. 


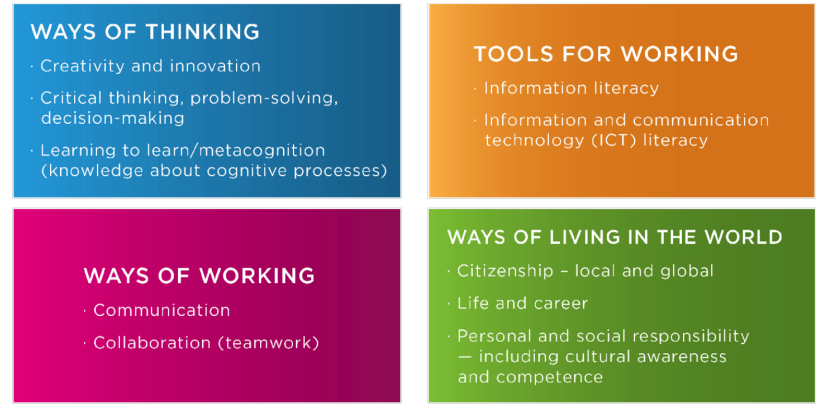

Fig. 2: ATC21s-defined 21st century skills framework (Credit: [21]).

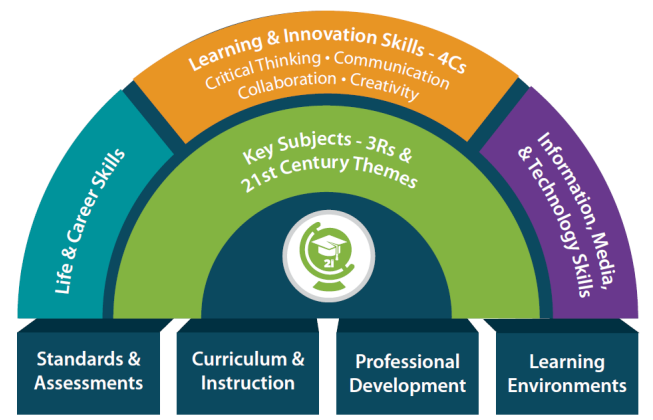

Fig. 3: The 21st century skills framework defined by P21 (Credit: [22]).

\section{P21-Defined 21st Century Skills Framework}

The Partnership for 21st Century Learning, or P21, was founded as a non-profit coalition that includes major corporations, including Cisco, Dell, Microsoft, and other companies. The P21 Framework champions 4Cs-Critical Thinking, Creativity, Collaboration, and Communication (see Figure 3) as the core 21st century skills. The P21 framework identifies six key 21 st century skills ${ }^{1}$. The framework covers the mastery of four foundations: a) key subjects (e.g., English, reading, or language arts, Mathematics, and Science) and 21st century themes (e.g., global awareness, civic literacy, and health literacy); $b$ ) life and career skills (e.g., navigation of the complex and globally competitive environments for life and work); c) learning and innovation skills (e.g., 4Cs); and d) information, media, and technology skills (e.g., information access and evaluation, as well as information use and management). Graduates are better prepared when the foundations are combined with the necessary support systems, including standards and assessments, curriculum and instruction, professional development, and learning environments.

\section{Other 21st Century Learning Frameworks}

Another prominent framework, which we have omitted due to space constraints, is the four dimension framework for $21 \mathrm{st}$ century learner proposed by the center of curriculum redesign (CCR) comprising "knowledge (what we know and understand), skills (how we use what we know), character (how we behave and engage in the world) and meta learning (how we reflect

\footnotetext{
${ }^{1}$ https://en.wikipedia.org/wiki/21st_century_skills
}

and adapt)" [23]. We refer the interested readers to review and comparison of the frameworks for 21 st century skills in [9].

\section{ESSENTIAL COMPETENCIES FOR BEYOND-2020S Future Electrical \& COMPUter Engineers}

In this section, we describe the essential competencies for beyond-2020s future electrical \& computer engineers. We have organized them in the following subsections (see Figure 4): (§III-A) metacognitive skills; (§III-B) technical skills; (§III-C) breadth skills; and (§III-D) inter-/intra-personal skills. (We note that we use the term "skills" synonymously as competencies, broadly as an umbrella term that subsumes skills, knowledge, as well as attitudes.)

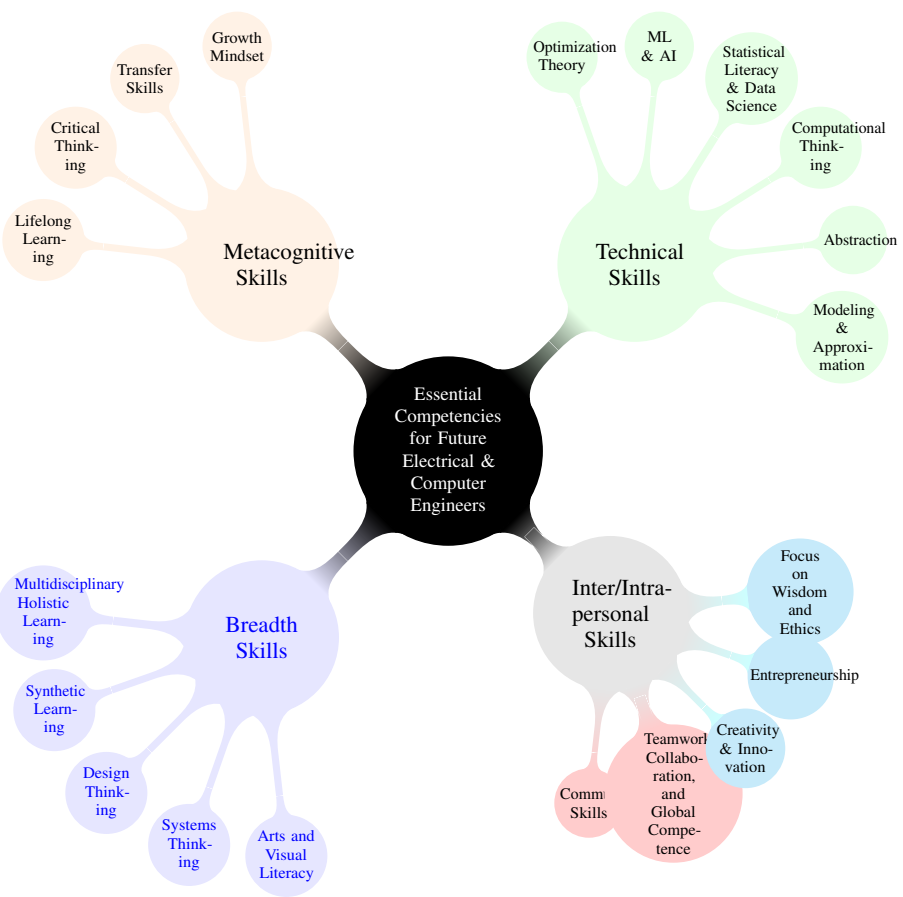

Fig. 4: A Mind Map of the Essential Competencies for Future Electrical \& Computer Engineers

\section{A. Metacognitive Skills}

"Metacognition is crucial to effective thinking and problem solving and is one of the hallmarks of expertise in specific areas of knowledge and skill. Experts use metacognitive strategies for monitoring understanding during problem solving and for performing self-correction."-National Research Council (NRC) 1999 volume titled How People Learn.

Humans have long wanted to understand our own minds. But it wasn't until the late 1970s that developmental psychologist John Flavell assigned a name to the concept. He defined metacognition as capturing "our knowledge about cognition and our regulation of the cognitive process" [24]. The same concept is sometimes referred to as "mental literacy", a term coined by Tony Buzan, to represent familiarity and understanding of the workings of the human mind. Gelb in his book Thinking Like Da Vinci [25] lists mental literacy (along with global literacy and computer literacy) as an essential attribute of the 
modern universal man. Metacognition is critical for effective thinking and problem solving and is considered as one of the hallmarks of expertise in specific areas of knowledge and skill. Broadly speaking, metacognition depends on two things: (1) knowing one's mental capabilities, and (2) being able to step back from problem-solving activities to evaluate one's progress. Recognition of one's prior knowledge and to have a good understanding of one's knowledge gaps is also a key aspect of metacognition for "anyone who does not know and does not know that he does not know is stuck forever in double ignorance" (the Persian polymath al-Tusi, cited in [26]). A richer awareness of one's mental models, and the biases that may arise [27], offers a stepping stone towards becoming a better thinker, learner, communicator, decision maker, and a team player [28] [29] [30]. More detailed research findings on learning and metacognition, and their implications for instruction and learning, are described in [31] [32]. Some of these principles are revisited in this paper in light of essential skills for future engineers. In the remainder of this section, we explain four important concepts (growth mindset, transfer skills, critical thinking, and lifelong learning) related to metacognition and knowledge of learning.

\section{1) Growth Mindset and Learning From Failures:}

"The mind is everything; what you think you become"-Socrates.

Psychologists have studied success, mastery, and achievement in diverse fields and in this regard have noticed the key role of hard work and mindset. To codify this, Carol Dweck, a Stanford professor and research leader in this field, has developed two distinct mindsets models [33]: the fixed mindset and the growth mindset. A person with a fixed mindset imagines intelligence or talent to be fixed human traits, which cannot be significantly developed. A person with a growth mindset, on the other hand, rightly attributes grit, hard work, and conscientiousness as a contributor to success and imagines intelligence or talent as traits that can be greatly enhanced through hard work and effort. Growth mindset is starkly different from fixed mindset in how it responds to failures and setbacks. People with a growth mindset treat failure as a learning opportunity rather than a terminal ailment. This is important since creative geniuses such as Mozart, Edison, etc., are quite prolific when it comes to failureit is just that they do not let failures stop them, instead taking failure as an opportunity to improvise and improve [34]. According to Dweck [33], regardless of one's ability, it is effort that ignites ability and turns it into accomplishment. It's important for future engineers to have training in mindset and emotional intelligence since experts have noted that all the key change variables of learning and educational transformation are emotional [4], [35]. It has been shown in previous work how shaping mindset can enhance educational outcomes, employability, and well being. ${ }^{2}$.

\section{2) Transfer Skills:}

"A primary goal of education is the development and deepening of student understanding of important ideas and processes within, and across, disciplines

\footnotetext{
${ }^{2} \mathrm{http} / / /$ www.olin.edu/sites/default/files/may_17_how_shaping_mindset_ can_enhance_educational_outcomes_employability_and_well-being.pdf
}

so that they can transfer their earning to new situations."-McTighe and Wiggins [36].

For 21 st century skills, we need to teach for understanding $\&$ transfer rather than for memorization of facts and information. Having transfer skills requires one to have deeper understanding, which go beyond memorization and recall of information towards deeper comprehension and application in novel settings [28]. Rote learning is the antithesis of the approach needed since rote learning not prepare students for transfer. To develop mastery, students must acquire component skills, practice integrating them, and know when to apply what they have learned. Transfer skills, in effect, translate to what Benjamin Bloom and his colleagues in their famous taxonomy refer to as "application" [37]. The key skill in acquiring transfer is to not only to recall memorized information but to modify, adjust, and adapt a general idea to the particulars of a situation. In the words of John Dewey [38], to grasp the meaning of a concept " is to see it in its relations to other things: to see how it operates or functions, what consequences follow from it, what causes it, what uses it can be put to." Without the development of transfer skills, students will not be able to understand a topic or subject and be able to use (or "apply," in Bloom's sense) knowledge and skill effectively.

A key finding in the learning and transfer literature is that organizing information into a conceptual framework allows for greater transfer. The promotion of transfer skills requires the learner to be aware of the "big ideas" of a field. These big ideas serve as the "conceptual velcro" to which all other concepts in the field connect. According to Wiggins and McTighe [36], "no skill can be integrated into a powerful repertoire unless the learner understands the big ideas related to using the skill wisely."

\section{3) Critical Thinking:}

"The function of education, therefore, is to teach one to think intensively and to think critically." Martin Luther King Jr.

To be a critical thinker implies the ability to think analytically and holistically, identify biases and logical fallacies, and to ask intelligent questions and to seek deeper understanding [28]. Many engineers are exposed exclusively to quantitative technical courses, but without critical thinking skills, derived from broad exposure to the arts, humanities, and social sciences, the students are at a disservice and are often unable to find the root cause of the problem which they are trying to solve technologically. Becoming a critical thinker also requires a greater awareness of purely technical solutions, models, and tools. Without this awareness, engineers are vulnerable to the Procrustean fallacy ${ }^{3}$, which inevitably results in fitting reality to our models and tools rather than the other way around. Critical thinking is also indispensable in the modern era as engineers have to live as responsible citizens in a world inundated with data and information. Critical thinking skills are sorely needed to evaluate and sift out the daily firehose of information that people must cope with. There is a greater awareness of critical thinking as a requirement for engineers and many accreditation

\footnotetext{
${ }^{3}$ This fallacy refers to Greek mythology figure Procrustes, who is known to be a robber who tied his victims to a bed and in order to make them fit either stretched their legs or cut them off
} 
boards now mandate coverage of courses that help develop critical thinking skills.

\section{4) Lifelong Learning:}

"Life is like riding a bicycle. To keep your balance you must keep moving."-Einstein

It is estimated that presently engineering knowledge has a doubling time, and information half-life (i.e., when half of the engineering information becomes obsolete), of roughly 5-10 years. ${ }^{4}$ When we add to this, the increased longevity of lifetimes (in many countries, a child born today has more than an even chance of living more than 100 years!), it becomes clear to see why it is critical to teach to engineers the ability and instrumental knowledge and engender a mindset for continuous lifelong learning. It is estimated that workers will now typically have 12 jobs in their lifetimes, many in areas other than their university specialization [39]. Duderstadt in his proposal "Engineering for a Changing World" [40] proposed that the engineering profession should also "develop a structured approach to lifelong learning for practicing engineers similar to those in medicine and law. This will require not only a significant commitment by educators, employers, and professional societies but possibly also additional licensing requirements in some fields." Harvard and some other universities are even formalizing the so-called 60-year curriculum to chart a plan for a lifetime of learning [41].

\section{B. Technical Skills}

More than anything else, engineers are characterized by their technical abilities - as an example, the Washington Accord graduate attribute \#1 is "an ability to apply knowledge of mathematics, science, engineering fundamentals and an engineering specialization to the solution of complex engineering problems". We discuss six such broad skills next that all future electrical and computer engineers should have exposure and reasonable mastery over.

1) Modeling \& Approximation: As we enter the 2020s, engineers have to work with unprecedentedly voluminous swathes of data for which they have to resort to models to make any sense of the data. By models, we mean mathematical structures or concepts that help us understand the world in a simplified fashion by capturing their most salient features [42]. As elaborated by Scott Page in his book [42], "models are formal structures represented in mathematics and diagrams that help us to understand the world. [...] mastery of models improves your ability to reason, explain, design, communicate, act, predict, and explore." Models are closely related to approximation as models themselves are economic approximations or explanations of the complex real world. To thrive in the coming VUCA world, it is important for engineers to have the ability to perform back-of-the-envelope calculations and make judicious use of approximations. In the words of John Tukey, "far better an approximate answer to the right question, which is often vague, than an exact answer to the wrong question, which can always be made precise."

\footnotetext{
${ }^{4}$ https://spectrum.ieee.org/view-from-the-valley/at-work/education/ the-engineers-of-the-future-will-not-resemble-the-engineers-of-the-past
}

2) Abstraction: Abstraction refers to "preserving information that is relevant in a given context, and forgetting information that is irrelevant in that context" [43]. The gamut of electrical and computer engineering is bridged by a number of abstractions. By using abstractions, engineers can quickly combine abstract components to develop new functionalities for solving new problems and addressing new challenges [44]. In an insightful description of the use of abstraction in electrical and computer engineering, Agarwal \& Lang [45] describe how a person playing a computer game works on a series of abstractions built on top of the other-more specifically, the game is built using a programming language abstraction, which depends on an assembly language abstraction, which depends on a microprocessor abstraction, which depends on a finite-state machine abstraction, which depends on a memory abstraction, which depends on a logic gate abstraction, which depends on a digital abstraction, which depends on a law of physics abstraction that models nature. This underscores the importance of the concept of abstraction is and demonstrates how germane it is to the field of engineering.

3) Computational Thinking: Just as reading, writing, and arithmetic has been a core competency for all literate people, computational thinking is now considered a core competency for all literate people. Computational thinking is especially relevant for future electrical and computer engineers in the modern AI era since it underlies the various topics (abstraction, data science, algorithms, pattern recognition, optimization) that have become indispensable for the modern information era [23] [43]. Apart from the computational skills, competency in computer programming is also now indispensable for engineers. Engineering artifacts now invariably have a software component and engineers need software skills to not only create new artifacts but also to understand and operate existing ones.

4) Statistical Literacy \& Data Science: Engineers are inundated with structured and unstructured, digital and nondigital, and quantitative and qualitative (e.g., image), data, in the era of big data, and their ability to translate it to information is essential to understand and analyze actual phenomena. Statistical tools have been used to collect, understand, process (e.g., aggregate), visualize, and analyze a massive amount of highly variable data to test hypotheses, make decisions, and draw conclusions. With the abundance of computing power and storage resources, Engineers must learn how to code and use machine learning or artificial intelligence approaches to conduct complicated analysis for solving complex problems.

5) Machine Learning \& Artificial Intelligence: We live in the era of machine learning (ML) and artificial intelligence (AI), where engineers routinely use datasets to develop ML and AI systems that learn from experience to improve its knowledge, which is applied to perform a wide range of tasks, such as classification, prediction, and optimization. These technologies, which originated from the computer and statistical sciences, now have become mainstream in most fields of electrical engineering including digital signal processing, control systems, communication systems, and electronics. Future electrical and computer engineers should have a strong technical grasp of ML and AI and should also have a grip on the social implications of such technology so that they may design effective engineering artifacts that benefit society. 
6) Optimization Theory: Engineers are mostly interested in utilizing scientific concepts to serve practical ends and in this regard they have certain objectives and certain constraints (or budget). Optimization theory is the mathematical field related to posing and optimally solving these engineering problems [46]. Optimization comes in many hues-e.g., combinatorial optimization, game theory, control theory. With the advances in the field, it is now possible in most practical cases to solve largescale problems having millions of variables and constraints. However subtle differences in how the problem is posed can transform a tractable problem into an intractable one. It is important for engineers to be educated in this field so that they can leverage the insights of the field to optimally solve their problem and create efficient engineering solutions.

7) Systems and Complexity Science: Contemporary advances in electrical and computer engineering-ranging from biomedical nanodevices to complex manufacturing designs to large-scale networked devices-increasingly require a perspective informed by systems and complexity science (which has been referred to as the science of the 21st century by luminaries such as Stephen Hawking and Edward O. Wilson). The need for system and complexity science insights arises from the fact that these domains have complex problems (sometimes called wicked problems) that defy common plain-minded solutions. More broadly, the leading problems the world faces today (e.g., climate change, water resources, energy policy, obesity, homeland security, corruption) are all complex problems that have arisen due to the lack of systemic thinking, and to, quote Einstein, "we cannot solve problems by using the same kind of thinking we used when we created them". There is wide agreement that future engineers should have the skills and knowledge related to how to address complex and ill-structured problems that involve different stakeholders, value conflicts, and uncertainty.

\section{Breadth Skills}

\section{1) Holistic Multidisciplinary Learning:}

"Most people are trained in one model-economics, for example - and try to solve all problems in one way. You know the old saying: 'To the man with a hammer, the world looks like a nail.' This is a dumb way of handling problems." - Charles Munger.

When it comes to defining 21 st century skills, there is increasing consensus that a whole-person education is needed rather than just vocational or technical training [15] [47] [48]. In this regard, a committee of the National Research Council of the NAE, USA, identified three distinct domains of competence: (1) cognitive, (2) intra-personal, and (3) interpersonal [15]. In the report "Designing the Future in Higher Education (GaTech): Whole Person Skills" [48], it is stated that "[Whole person education] addresses the importance of experiential learning, globalization at home, professional development of graduate students that fuses traditional research-oriented training with whole person education, and a whole person curriculum that emphasizes interpersonal and intra-personal competencies along with cognitive accomplishments."

Apart from developing a deep understanding of content, subject matter, and knowledge in a particular discipline, becoming a broad thinker requires understanding similar patterns that underlie and transcend multiple disciplines so that the learner may make deep interconnections, develop insights, and discover new knowledge [28]. To be a holistic thinker, one's learning should extend to all the various types of human learning-i.e., the cognitive (knowing, or head), the affective (emotions, feelings, or heart), as well as the psychomotor (doing, or kinesthetic, tactile, haptic or hand/body) —as well as domains of knowledge (including qualitative as well as quantitative fields).

This often opens a question regarding the balance between depth and breadth. Although we are proposing breadth in one's vision and learning, it's important to note that such breadth should not be construed to mean becoming a jack of all trades and master of none. On the contrary, the right balance complements general breadth with focused depth in some areas. Some authors refer to this as being a T-shaped engineer [49] with the engineer (like the letter T) should have depth in some field apart from a broad exposure to the important ideas in philosophy, psychology, history, economics, significant insights about subjects of enduring interest to human beings.

\section{2) Synthetic Thinking and Integrative Thinking:}

"The mark of a creative scientist, whatever aspect of the natural world the scientist is studying, is the extent to which he or she can combine hard, verifiable experience with imaginative explanations." [50]

Howard Gardner, writing in his book titled The Five Minds for the Future [51], describes the synthesizing mind to be one that will play a pivotal role in the modern information-inundated world, where the ability to work with and synthesize disparate information is very valuable [52]. The ability to entertain two opposing ideas or confusing ideas and to synthesize and integrate them to find reasonable conclusions is a critical skill for the modern VUCA world. Gelb lists in his book Thinking Like Da Vinci [25], the ability to endure confusion as a distinctive trait of highly creative people while Scott Fitzgerald is reported to have said that it is a test of a firstrate intelligence to have "the ability to hold two opposing ideas in the mind at the same time, and still retain the ability to function". Apart from synthetic thinking, future engineers should also have divergent skills or lateral thinking abilities to help see different possibilities [53].

It is also important for future engineers to adopt a manymodel thinking approach [42]. The famous fable of the elephant and the seven blind men is instructive here: the story goes that seven blind men came across an elephant, each of which had a different conception of the elephant (one touched the legs of the elephant and imagined it to be a tree trunk; another touched the back and imagined it to a wall; another handled the tusk and imagined it to be a spear). While each of the blind man were wrong, they could have collectively figured out that it is an elephant by synthesizing and integrating the various models they had arrived at. Using a many-model approach, one can reason better; understand complex phenomena better; have fewer gaps in one's reasoning; make more robust decisions; and become wiser. Without using multiple models, one is blind to our blindness (i.e., the blind spots of our mental models through which we are understanding reality).

\section{3) Design Thinking:}


"Good design is a renaissance attitude that combines technology, cognitive science, human need, and beauty to produce something that the world didn't know it was missing."-Paola Antonelli.

To become a design thinker one should be able to reduce things or ideas to the essential structure, attend to both function and form, and have the ability to develop simple yet effective solutions under existing constraints [28] [54]. Design thinking and a focus on making is now becoming a big global trend [55]. Many innovative modern universities, such as Singapore University of Technology and Design (SUTD) have merged design and technology together in their name as well as their motto ("a better world by design"). Design thinking has now emerged as a methodology for innovating routinely and it is taught to entrepreneurial engineers globally (Stanford's d.school [56] and Harvard [57] are premier examples of institutes focused on design thinking). Design thinking is especially critical for engineering where design, and in particular design under constraints, is a perennial concern.

\section{4) Systems Thinking:}

"There is always an easy solution to every problemneat, plausible and wrong."-H. L. Mencken.

We can define a system as, "an interconnected set of elements that is coherently organized in a way that achieves something" [58]. Systems thinking can help us more more clearly see the deviation of a system from the defined purpose and to effectively reconcile. Systems thinking is distinguished by other ways of thinking by simultaneously using holism (seeing everything as a part of a larger whole) and reductionism (splitting things into their constituent parts). To be a system thinker means developing the skill to see the bigger perspective and the wider context of a situation so that unintended undesirable consequences can be thwarted [28]. Systems thinking is an antidote to the exclusive focus on reductionist principles but as has been shown by the recent developments in complex systems, the whole is greater than the sum of its parts (this is of course not a new finding and Aristotle is reported to have said these same words more than 2000 years ago). Another goal of systems thinking is the continuous refinement of mental models through the incorporation of complex interactions to align these models better with the real world [28].

Systems thinking is especially appropriate for complex problems known as "wicked problems", which are often found in complex adaptive social systems. Wicked problems are those stubborn problems that defy simple intuitive solutions and in which symptoms often deteriorate due to "solutions" producing fresh problems. These problems are not totally hopeless though-it has been shown significant, enduring improvements can be produced through small well-focused actions when they're applied at the right place in the right way. Systems thinkers refer to this principle as the "principle of leverage" and to system thinkers resolving a problem often boils down to finding interventions that are high leverage. Systems thinking is also good for avoiding the rut of producing the problems of tomorrow by today's solutions [28]. As noted in NAE's report on Educating the Engineer of 2020 [5], it is important that future students are taught apart from their technical courses the broad impacts of their work on the environment, society, and the economy. ${ }^{5}$ This is especially important for tackling the biggest problems facing humanity such as sustainability, not tackling which can have dire consequences for the planet [59].

\section{5) Arts and Visual Literacy:}

"The greatest value of a picture is when it forces us to notice what we never expected to see."-J. Tukey

In many modern engineering universities, there are limited options for, or emphasis on arts and visual literacy. In [60], Goldberg identifies the inability of modern engineering education to nurture an ability to visualize solutions and generate ideas as a major failing. Experts have long recognized the importance of arts in the education of engineers. For example, NAE in 2004 looked at the grand challenges that lay ahead for "the Engineer of 2020," and noted that it will no longer be sufficient for future engineers to be grounded only in the basics of quantitative subjects such as math and science and that engineers will need to "understand and appreciate history, philosophy, culture, and the arts, along with the creative elements of all of these disciplines." This is in a way a throwback to the renaissance engineers, such as Leonardo Da Vinci, who was both an ultimate engineer as well as an artist [25].

\section{Intra/Inter-Personal Skills}

In this section, we detail five important interpersonal and intrapersonal skills especially relevant for future electrical and computer engineers. Of these, the first two (communication skills and teamwork/global competence) can be said to be interpersonal skills while the latter three (creativity, entrepreneurship, wisdom and ethics) are intrapersonal skills.

\section{1) Communication Skills:}

"Poor communication skill is the Achilles' heel of many engineers, both young and experienced-and it can even be a career showstopper." [61]

Language skills are a major contributor to a whole-person education through which various "people skills" are learned and honed. We are a literate species - it is our literacy and our ability to speak highly-developed languages that distinguish us from other animals. It also turns out for an average engineerwho has spent the majority of their time at the university on difficult technical subjects in science, mathematics, and engineering - spends less than half of their typical working day using technical skills with most of the time taken up by reading, writing, presenting, communicating, something that was often left as an exercise to the student at universities. In [60], Goldberg identifies the inability of modern engineering education to nurture an ability to communicate solutions in written and oral form as a major failing. Communication is a timeless skill, and with most other modern skills being shortlived, communication has become an essential 21 st century skill. It is very important for future engineers to develop excellent communication skills (including writing as well as presentation skills) to thrive in the future information-laden environment that will communicate in myriad ways [62].

\footnotetext{
${ }^{5}$ Canadian Engineering Accreditation Board (CEAB) describes the following as essential graduate attributes: "deal with complexity, and is skilled at systems thinking".
} 


\section{2) Teamwork, Collaboration, and Global Competence:}

"The research evidence is conclusive: inquiry, design, and collaborative approaches to learning build a powerful combination of content understanding, basic skills, and applied 21st century skills" [2]

The 21 st century is the century of networking with new tools for collaboration allowing the formation of global teams working in conjunction. The ability to work in teams and to learn and solve problems in a collaborative team setting is an essential skill that will be critical to the success of future engineers and engineering students. In addition, it is vital for future engineers to have the "ability to demonstrate management skills and apply engineering principles to one's own work, as a member and/or leader in a team, to manage projects in a multidisciplinary environment" (Washington Accord Graduate Attribute 11, Project Management).

Developing global competence requires the development of prosocial thinking in which one recognizes oneself as a citizen of a larger community and begins to appreciate diversity and different cultures, traditions, and ways of thinking. A global citizen must think independently and be open-minded. Through this, one can develop effective communication skills and deeper rapport with all humanity and also become a better pro-social human being [28]. Universities can adopt various strategies for global competence including the institution of special courses on world cultures and languages as well as arranging international experiences for students through academic exchanges and study abroad programs, collaborative research and design projects with international universities, international co-ops or internships, and dual degree programs with international universities [10].

\section{3) Creativity \& Innovation:}

"Many pedagogical experts argue that schools should switch to teaching 'the four Cs'-critical thinking, communication, collaboration and creativity."Yuval Noah Harari [63].

To be a creative thinker implies the ability to be inventive, ingenious, and insightful to create new ideas, inventions, and innovations [28]. Creativity is a much-craved attribute: in an IBM survey of more than 1,500 CEOs, creativity was described as the single most important leadership attribute for enterprises that face the complexity of global commerce today [64]. Creativity can be enhanced through increased interactions across different disciplinary boundaries and by an interactive blending of feeling and thinking [65]. Engineering, when done well, is one of the best ways to nurture and build creativity skills for engineering at its core is essentially a creative enterprise. While scientists ask "why?", engineers must ask "why not?" [4] [66]. While science overall is focused on exploring what exists, engineering is an optimistic profession focused on imagining and creating useful inventions and machines which have never existed before. The word engineer has its etymological roots in the Latin word ingeniator, related to the word ingenious, which means to devise in the sense of craftsmanship. Unfortunately, most schools and universities are not designed to encourage creativity-perversely, most schools actively suppress creativity due to the their emphasis on discipline and uniformity. According to Sir Ken Robinson, "creativity is as important in education as literacy, and we should treat it with the same status".

\section{4) Entrepreneurship:}

"Entrepreneurship is a mindset, an outlook that shapes the way you see the world and the possibilities that it holds. It [...] is the courage to say to yourself, "This could be better"." [67]

According to the authors of Whole New Engineer [4], a key attribute of effective future engineers would be an entrepreneurial propensity. This propensity emerges from having creative confidence that can unleash the creative potential within us and instill a belief in our ability to create change in the world around us for the better [34]. Such creative confidence needs to be nurtured through effort, which will give us the ability to come up with new ideas and also the courage to try out these ideas. This requires a deep shift in the perspectives of universities as well as students so that the courage of treading new path is instilled rather than obedience to authority and conventions.

\section{5) Focus on Wisdom and Ethics:}

"A scholar knows many books; a well-educated person has knowledge and skills; an enlightened person understands the meaning and purpose of his life."-Leo Tolstoy.

In the world of "information theory", "knowledge economy", and "data science", it is certainly out of fashion to talk about wisdom-however wisdom is especially needed as it allows the application of knowledge towards humane goals and it helps in ascertaining which models are appropriate for which tasks. Wisdom is qualitatively different from data, information, and knowledge and is an extremely valuable general-purpose for the modern VUCA world in which disinformation and ethical dilemmas are rife. In such settings, wisdom is important as it provides the ability to deal with change, to learn new things, and to apply the right mental model and ideal in unfamiliar situations. It is also extremely important for engineers to have ethical knowledge and resolve to act ethically-the Washington Accord has a specific graduate attribute related to ethics, which requires that graduates should have the ethical attribute that enables them to "apply ethical principles and commit to professional ethics and responsibilities and norms of engineering practice."

\section{Conclusions}

In this paper, we have ruminated on the necessary knowledge, skills, attitudes, and mindset that future electrical and computer engineers should have as we move into the 2020s. In the past, several efforts have focused on distilling important $21 \mathrm{st}$ century skills. Our paper builds upon these prior works and describes-particularly for electrical and computer engineersthe essential attributes that they must have to thrive in the future, which will be more and more volatile, uncertain, complex, and ambiguous. We organize these essential competencies in four areas: metacognitive skills, technical skills, breadth skills, and inter/intra-personal skills. Our work is timely as the electrical and computer engineering community needs a special focus on the essential competencies we have highlighted to thrive in the coming volatile, uncertain, complex, and ambiguous (VUCA) times. 


\section{REFERENCES}

[1] D. H. Pink, A whole new mind: Why right-brainers will rule the future Penguin, 2006.

[2] B. Trilling and C. Fadel, 21st Century Skills: Learning for Life in Our Times. John Wiley \& Sons, 2009.

[3] A. Chalah, D. Hwang, and F. Habbal, "Current directions in modern undergraduate engineering education," Transforming Institutions: Undergraduate STEM Education for the 21st Century, p. 245, 2015.

[4] D. E. Goldberg and M. Somerville, "A whole new engineer," The coming revolution in Engineering Education. Douglas MI: Threejoy, 2014.

[5] B. E. Seely, "Patterns in the history of engineering education reform: A brief essay," Educating the engineer of 2020: Adapting engineering education to the new century, pp. 114-130, 2005.

[6] B. Ayazifar, "Can we make signals and systems intelligible, interesting, and relevant?," IEEE Circuits and Systems Magazine, vol. 9, no. 1, pp. 48-58, 2009.

[7] E. A. Lee and D. G. Messerschmitt, "Engineering an education for the future," Computer, vol. 31, no. 1, pp. 77-85, 1998.

[8] F. C. Berry, P. S. DiPiazza, and S. L. Sauer, "The future of electrical and computer engineering education," IEEE Transactions on Education, vol. 46, no. 4, pp. 467-476, 2003.

[9] C. Dede, "Comparing frameworks for 21 st century skills," 21 st century skills: Rethinking how students learn, vol. 20, pp. 51-76, 2010

[10] S. A. Rajala, "Beyond 2020: Preparing engineers for the future," Proceedings of the IEEE, vol. 100, no. Special Centennial Issue, pp. 13761383, 2012.

[11] U. National Academy of Engineering, The engineer of 2020: Visions of engineering in the new century. National Academies Press Washington, DC, 2004

[12] I. Phase et al., Educating the engineer of 2020: Adapting engineering education to the new century. National Academies Press, 2005.

[13] F. E. Terman, "A brief history of electrical engineering education," Proceedings of the IEEE, vol. 86, no. 8, pp. 1792-1800, 1998.

[14] J. E. Froyd, P. C. Wankat, and K. A. Smith, "Five major shifts in 100 years of engineering education," Proceedings of the IEEE, vol. 100 no. Special Centennial Issue, pp. 1344-1360, 2012.

[15] N. R. Council et al., Education for life and work: Developing transferable knowledge and skills in the 21st century. National Academies Press, 2013.

[16] P. D. Galloway, "The 21st-century engineer: A proposal for engineering education reform," American Society of Civil Engineers, 2007.

[17] J. E. King, "Educating engineers for the 21st century," International Engineering Education, R. Natarajan (ed.), INAE, Madras, India, pp. 3 $28,2009$.

[18] N. Spinks, N. Silburn, and D. Birchall, "Educating engineers for the 21st century: The industry view,' London: The Royal Academy of Engineering, 2006.

[19] R. Hoyle and E. Davisson, "Assessment of self-regulation and related constructs: Prospects and challenges," in NRC Workshop on Assessment of 21st Century Skills. Available: http://www7. nationalacademies. org/bota/21st_Century_Workshop_Hoyle_Paper. pdf [October 2011] 2011.

[20] M. t. Binkley, Defining Twenty-First Century Skills. Springer, 2012

[21] M. Binkley, O. Erstad, J. Herman, S. Raizen, M. Ripley, M. Miller-Ricci, and M. Rumble, "Defining twenty-first century skills," in Assessment and teaching of 21st century skills, pp. 17-66, Springer, 2012.

[22] P. for 21st Century Skills (P21), "P21's framework for 21st century learning." http://www.p21.org/, Accessed on: 6-April-2020.

[23] C. Fadel, M. Bialik, and B. Trilling, Four-dimensional education. 2015

[24] J. H. Flavell, "Metacognition and cognitive monitoring: A new area of cognitive-developmental inquiry.," American psychologist, vol. 34 no. 10 , p. 906, 1979.

[25] M. J. Gelb, How to think like Leonardo da Vinci: Seven steps to genius every day. Dell, 2009.

[26] W. Ahmed, The Polymath: Unlocking the Power of Human Versatility. John Wiley \& Sons, 2019.

[27] R. Dobelli, The art of thinking clearly: better thinking, better decisions. Hachette UK, 2013.

[28] D. Cabrera and L. Cabrera, Systems thinking made simple. Independently published, 2015

[29] J. Qadir, "What every student should know: Seven learning impediments and their remedies," IEEE Potentials, vol. 34, no. 3, pp. 30-35, 2015.

[30] J. Qadir and M. A. Imran, "Learning 101: The untaught basics," IEEE Potentials, vol. 37, no. 3, pp. 33-38, 2018

[31] J. D. Bransford, A. L. Brown, R. R. Cocking, et al., How people learn, vol. 11. Washington, DC: National academy press, 2000.
[32] S. A. Ambrose, M. W. Bridges, M. DiPietro, M. C. Lovett, and M. K Norman, How learning works: Seven research-based principles for smart teaching. John Wiley \& Sons, 2010.

[33] C. Dweck, Mindset: The new psychology of success. Random House LLC, 2006.

[34] T. Kelley and D. Kelley, Creative confidence: Unleashing the creative potential within us all. Currency, 2013.

[35] J. Medina, Brain rules: 12 principles for surviving and thriving at work home, and school. Pear Press, 2011.

[36] G. Wiggins and J. McTighe, Understanding by design. ASCD, 2005.

[37] B. S. Bloom et al., "Taxonomy of educational objectives. vol. 1: Cognitive domain," New York: McKay, pp. 20-24, 1956.

[38] J. Dewey, How we think. Courier Corporation, 1997.

[39] L. Gratton and A. Scott, The 100-year life: Living and working in an age of longevity. Bloomsbury Publishing, 2016.

[40] J. J. Duderstadt, "Engineering for a changing world," in Holistic engineering education, pp. 17-35, Springer, 2010.

[41] C. J. Dede and J. Richards, The 60-Year Curriculum: New Models for Lifelong Learning in the Digital Economy. Routledge, 2020.

[42] S. E. Page, The Model Thinker: What You Need to Know to Make Data Work for You. Hachette UK, 2018.

[43] J. Guttag, Introduction to computation and programming using Python: With application to understanding data. MIT Press, 2016.

[44] B. Liskov, "Keynote address-data abstraction and hierarchy," in Addendum to the proceedings on Object-oriented programming systems, languages and applications (Addendum), pp. 17-34, 1987

[45] A. Agarwal and J. Lang, Foundations of analog and digital electronic circuits. Elsevier, 2005.

[46] G. C. Calafiore and L. El Ghaoui, Optimization models. Cambridge university press, 2014.

[47] R. K. Miller, "Why the hard science of engineering is no longer enough to meet the 21st century challenges," Olin College of Engineering, 2015

[48] L. V. Morris, "Designing the future in higher education," Innovative Higher Education, vol. 43, no. 5, pp. 321-322, 2018.

[49] J. Tranquillo, "The t-shaped engineer," Journal of Engineering Education Transformations, vol. 30, no. 4, pp. 12-24, 2017.

[50] R. L. Ackoff and D. Greenberg, Turning Learning Right Side Up: Putting Education Back on Track (paperback). Pearson Prentice Hall, 2008.

[51] H. Gardner, "The five minds for the future," 2009.

[52] R. L. Martin, The opposable mind: How successful leaders win through integrative thinking. Harvard Business Press, 2009.

[53] E. De Bono, Lateral thinking: a textbook of creativity. Penguin UK 2010 .

[54] R. Razzouk and V. Shute, "What is design thinking and why is it important?," Review of educational research, vol. 82, no. 3, pp. 330-348, 2012.

[55] R. Grubb, J. Reich, E. Huttner-Loan, A. Napier, and G. Beazley, "Design thinking for leading and learning in review," 2017.

[56] B. Banerjee and T. Gibbs, "Teaching the innovation methodology at the stanford d. school," in Creating Innovation Leaders, pp. 163-174, Springer, 2016.

[57] B. Altringer and F. Habbal, "Embedding design thinking in a multidisciplinary engineering curriculum," in VentureWell. Proceedings of Open, the Annual Conference, p. 1, National Collegiate Inventors \& Innovators Alliance, 2015.

[58] D. Meadows, J. Randers, and D. Meadows, Limits to growth: The 30-year update. Chelsea Green Publishing, 2004.

[59] J. Lönngren, Wicked Problems in Engineering Education: Preparing Future Engineers to Work for Sustainability. Chalmers University of Technology, 2017

[60] D. E. Goldberg, "The missing basics and other philosophical reflections for the transformation of engineering education," in Holistic Engineering Education, pp. 145-158, Springer, 2010.

[61] D. F. Beer and D. A. McMurrey, A Guide to Writing as an Engineer. John Wiley \& Sons, 2019.

[62] M. J. Riemer, "Communication skills for the 21st century engineer,' Global J. of Engng. Educ, vol. 11, no. 1, pp. 89-100, 2007.

[63] Y. N. Harari, 21 Lessons for the 21st Century. Random House, 2018.

[64] IBM., Capitalizing on complexity: Insights from the global chief executive officer study. IBM, 2010.

[65] K. Robinson, L. Minkin, E. Bolton, D. French, L. Fryer, S. Greenfield and L. Green, "All our futures: Creativity," Culture and Education, Report for the Secretary of State for, 1999.

[66] R. K. Miller, "“from the ground up" rethinking engineering education in the 21 st century," 2010.

[67] D. E. Goldberg, The entrepreneurial engineer: personal, interpersonal, and organizational skills for engineers in a world of opportunity. John Wiley \& Sons, 2006 